\title{
Study on Modeling and Solving for Reactive Power Optimization of Large-scale Wind Power Integration
}

\author{
Deyu Chen \\ School of Computer and Informatin Engineering \\ Harbin University of Commerce \\ Harbin,China, 150028 \\ cdy1974610@sohu.com
}

\begin{abstract}
Based on large-scale wind power base of our country, the modeling and solving for multi-objective reactive power optimization of large-scale wind power integration are studied. To make sure of the hierarchical and regional balance of reactive power under normal circumstances and to have the power of supporting the safety of the grid in case of emergency, a solving thinking presents that capacitor switching and transformer tap adjusting and other discrete equipments are first, and the action sequence of generator and dynamic reactive power devices and other continuous equipments setting follows, which is presented that optimization problem is decomposed into continuous variable optimization and discrete variable optimization. The genetic algorithm is presented for finding global optimal solution. The coding of control variables and strategies for the cross and mutation operation are mainly studied, and determine each objective weight of multi-objective optimization. Case studies show that the proposed thinking is reasonable.
\end{abstract}

Keywords: wind power integration; reactive power optimization; power loss; voltage quality; voltage stability; genetic algorithm

\section{Introduction}

Wind power is developing at large pace in the need of energy and environmental sustainability nowadays. Large-scale wind power bases of China in plan are gradually carrying out the construction, the areas of wind power integration are most weak in grid, and the base load there is always small, as a result a large number of wind power needs to be transmitted out[1]. And in the process of transmission, the random changes in wind power output will have a great impact on the grid nearby. There might have the risks of Imbalances in the distribution of reactive power and unbalanced voltage fluctuations, and might cause problems such as voltage instability which are more serious[2]. The problem of multi-objective reactive power optimization of wind power integration on optimization of power loss, voltage quality and voltage stability after wind power integration needs to be solved.

The difficulty of multi-objective reactive power optimization is the coexistence of discrete and continuous variables and the optimization complexity, the optimization is multi-objective. Much research has been done on this problem. Paper [3] uses the novel quadratic penalty function to handle with discrete variables for Newton optimal power flow. Paper [4] discusses in detail about the theory of penalty function dealing with discrete variables and how to bind to Primal-dual interior point method directly and presents a new method to solve the problem of reactive power optimization in large-scale power systems with discrete variables. The disadvantage of methods above is that it's hard to achieve to the best optimal solution within an acceptable time. And Modern optimization techniques such as the simulated annealing algorithm, the tabu search method and the genetic algorithm (GA) and other strategies of 
randomly optimization[5-7,13], can guarantee to achieve to the best optimal solution within an acceptable time in principle, and are easy to deal with discrete variables. And among them the genetic algorithm(GA) on reactive power optimization is quite attractive. Though certain achievements have been made on the study of multi-objective reactive power optimization considering the coexistence of discrete variables and continuous variables, more research and investigation should be made to solve the problem better $[8,9]$.

A method of multi-objective reactive power optimization of wind power integration based on genetic algorithm with adaptive weight is presented. Case studies show that the proposed model, thinking and algorithm are reasonable.

\section{Multi-objective Model of Reactive Power Optimization}

$$
\begin{gathered}
\min F=\min \left(F_{1}, F_{2}, F_{3}\right) \\
=\min \left(P_{l o s s}\left(\boldsymbol{V}_{g}, \boldsymbol{c}, \boldsymbol{b}\right),-M\left(\boldsymbol{V}_{g}, \boldsymbol{c}, \boldsymbol{b}\right), \sum_{i=1}^{n}\left(V_{i}\left(\boldsymbol{V}_{g}, \boldsymbol{c}, \boldsymbol{b}\right)-V_{e}\right)^{2}\right) \\
\boldsymbol{f}\left(\boldsymbol{\theta}, \boldsymbol{V}_{l}, \boldsymbol{V}_{g}, \boldsymbol{c}, \boldsymbol{b}\right)=0 \\
\underline{\boldsymbol{V}}_{l} \leq \boldsymbol{V}_{l} \leq \overline{\boldsymbol{V}}_{l} \\
\underline{\boldsymbol{V}}_{g} \leq \boldsymbol{V}_{g} \leq \overline{\boldsymbol{V}}_{g} \\
\underline{\boldsymbol{Q} \boldsymbol{G}} \leq \boldsymbol{Q \boldsymbol { G }} \leq \overline{\boldsymbol{Q G}}^{\boldsymbol{\boldsymbol { c }}} \leq \boldsymbol{c}_{j} \leq \overline{\boldsymbol{c}}_{j} \\
\underline{\boldsymbol{b}}_{t} \leq \boldsymbol{b}_{t} \leq \overline{\boldsymbol{b}}_{t}
\end{gathered}
$$

s.t.

Where : F stands for multi-objective, the optimization objective can be expressed as $\min \left(\mathrm{F}_{1}, \mathrm{~F}_{2}, \mathrm{~F}_{3}\right)$, which represent lowering power loss, improving voltage stability and voltage quality. $\mathrm{F}_{1}=\mathrm{P}_{\text {loss }}($.$) is power loss, \mathrm{M}($.$) is load margin characterizing static voltage$ stability calculated from continuation power flow method, $\mathrm{F}_{2}=-\mathrm{M}(.) .\left(\mathrm{V}_{\mathrm{i}}(.)-\mathrm{V}_{\mathrm{e}}\right)^{2}$ represents voltage quality of node i. $F_{3}$ is the sum of voltage quality of all nodes in grid. $\mathrm{V}_{\mathrm{g}}$ is controlled bus voltage of dynamic reactive power compensation(DRPC) devices and terminal bus voltage of the conventional generator, collectively referred to as controlled bus voltage. $\mathrm{c}$ is the equivalent susceptance of switched capacitor. $\mathrm{b}$ is the tap ratio of the transformer. $\mathrm{V}_{\mathrm{g}} 、 \mathrm{c} 、 \mathrm{~b}$ are control variables. $\mathrm{f}($.) is equality constraints of power flow. $\theta$ is the phase angle of the voltage of all nodes. $\mathrm{V}_{1}$ is the voltage amplitude of load node. $\overline{\boldsymbol{V}}_{l}$ and $\underline{V}_{l}$ are the upper and lower of the voltage amplitude of load node, given as 1.05 and 0.95. $\bar{V}_{s}$ and $\underline{V}_{s}$ are the upper and lower of controlled bus voltage, given as 1.1 and 0.9 . QG is the reactive power output of the generator and DRPC devices. $\overline{Q G}$ and $\underline{Q G}$ are the upper and lower of reactive power output of the generator and DRPC devices. $\bar{c}_{j}$ and $\underline{c}_{j}$ are the upper and lower of equivalent susceptance of switched capacitor. $\overline{\boldsymbol{b}}_{t}$ and $\underline{\boldsymbol{b}}_{t}$ are the upper and lower of the tap ratio of the transformer.

\section{The Coordinated Regulation of Discrete and Continuous Variables}

When the faults that may compromise the power system security occurs, in order to make the power system recover back to safety, the fastly-responsed and continuouslyadjusted generator and DRPC devices are needed because the adjustable capacity of single discrete equipments is small and the response time is slow. As a result, from the perspective of improving system security, under normal circumstances the capacitor switching and transformer tap adjusting and other discrete equipments are first to leave a large margin adjustment for generator and DRPC devices.

In summary, discrete equipments are first and then are continuous equipments. Furthermore, a thinking on cross iteration between discrete variable optimization and continuous variable optimization: 
1) Set controlled bus voltage of continuous variable as rated voltage 1 , that is to say $\mathrm{V}_{\mathrm{g}}(0)=1$. Set the number of the iterative optimization $\mathrm{k}=1$.

2) Feed $V_{g}(k-1)$ into the model of reactive power optimization (1),considering only discrete variables. Set the ratio of the capacitor $\mathrm{c}(\mathrm{k})$ and the transformer as the variable $\mathrm{b}(\mathrm{k})$, and define this model as the model of discrete variable optimization (1.1). Solve the model (1.1) and get the optimal solution of discrete variables of $\mathrm{k}$-th iteration $\mathrm{c}(\mathrm{k})$ 、 $\mathrm{b}(\mathrm{k})$.

3) Feed $c(k), b(k)$ into the model of reactive power optimization (1), considering only continuous variables $\mathrm{Vg}$. Set the controlled bus voltage as the variable, and define this model as the model of continuous variable optimization (1.2). Solve the model (1.2 ) and get the continuous variable $\mathrm{V}_{\mathrm{g}}(\mathrm{k})$.

4) If $\mathrm{k}>1$ and meet the condition that ${ }^{\max }\left(\left|\boldsymbol{F}_{s}(k)-\boldsymbol{V}_{s}(k-1)\right|\right)<\varepsilon_{c}, \max (|\boldsymbol{c}(k)-\boldsymbol{c}(k-1)|)<\varepsilon_{c}, \max (|\boldsymbol{b}(k)-\boldsymbol{b}(k-1)|)<\varepsilon_{b}$, then quit the iteration, and the optimal solution is $\operatorname{Vg}(\mathrm{k}), \mathrm{c}(\mathrm{k}), \mathrm{b}(\mathrm{k})$. Otherwise if $\mathrm{k}>1$ and any $\max ()<.\varepsilon$ below does not hold, go to next.

5) Optimize the number of iteration $\mathrm{k}=\mathrm{k}+1$, and turn to step 2).

\section{The Solution of the Genetic Algorithm with Adaptive Weight}

\subsection{The Coding of Control Variables}

Use binary code, suppose the interval of integer variables is $[a, b]$, the length of the interval is $b$-a, divide the interval into $b$-a pieces:

$$
2^{k-1}<b-a \leq 2^{k}
$$

The length of the binary string of this code is $\mathrm{k}$ bits at least.

The transformation of binary string of $\mathrm{k}$ bits $\left(b_{k-1} b_{k-2} \cdots b_{0}\right)$ to the corresponding integer in the interval $[\mathrm{a}, \mathrm{b}]$ needs the following two steps:

1) Change the binary number of the binary string to decimal number:

$$
\left(b_{k-1} b_{k-2} \cdots b_{0}\right)_{2}=\left(\sum_{j=0}^{k-1} b_{j} \cdot 2^{j}\right)_{10}=i^{\prime}
$$

2) i' corresponds the integer i of the interval $[a, b]$ :

$$
i=a+\operatorname{int}\left(i \cdot \frac{b-a}{2^{k}-1}\right)
$$

4.1.1. The Coding of Continuous Variable-controlled Bus Voltage: Solve model of continuous variable optimization (1.2) , and code the control variable $\mathrm{Vg} . \overline{\boldsymbol{V}}_{s}$ and $\underline{V}_{s}$ are 1.1 and 0.9 , and suppose adjustable step is 0.01 , then $(1.1-0.9) / 0.01=20,24<20-0<25$, so the bit of binary code of controlled bus voltage of a continuous controlled equipment is 5 . When there are $\mathrm{n}$ continuous controlled equipments are in adjustment, the bit of binary code is $5 \times \mathrm{n}$. The coding of controlled bus voltage of continuous variable is as follows:

$$
V_{n, 4} V_{n, 3} V_{n, 2} V_{n, 1} V_{n, 0}\left|V_{n-1,4} V_{n-1,3} \cdots V_{n-1,0}\right| \cdots \cdots \mid V_{1,4} V_{1,3} V_{1,2} V_{1,1} V_{1,0}
$$

In them $\left(\mathrm{V}_{\mathrm{n}, 4} \mathrm{~V}_{\mathrm{n}, 3} \mathrm{~V}_{\mathrm{n}, 2} \mathrm{~V}_{\mathrm{n}, 1} \mathrm{~V}_{\mathrm{n}, 0}\right)$ stands for the binary code of the controlled bus voltage of one equipment, and $\mathrm{V}=0$ or 1 . Via (3) and (4), the binary code can be recovered into the set voltage of controlled bus :

So the controlled bus voltage is:

$$
\left(V_{4} V_{3} V_{2} V_{1} V_{0}\right)_{2}=\left(\sum_{j=0}^{4} V_{j} \cdot 2^{j}\right)_{10}=i^{\prime} \quad i=0+\operatorname{int}\left(i^{\prime} \cdot \frac{20-0}{2^{5}-1}\right)
$$

$$
V_{g}=0.9+i \times 0.01
$$

This coding of controlled bus voltage of continuous variable also implicit the inequality constraint of bus voltage $\underline{V}_{s} \leq V_{s} \leq \bar{V}_{s}$. 
4.1.2. The Coding of Discrete Variable-capacitor switching: Solve the model of discrete variable optimization (1.1) , and code the capacitor switching, one of the control variables. Suppose there are capacitors in node $\mathrm{i}_{\mathrm{j}}(\mathrm{j}=1,2, \cdots, \mathrm{n})$, and the equivalent susceptance of a capacitor in node ij is ce,j, and the range of the capacitors is $\left[\underline{c}_{j}, \bar{c}_{j}\right]$, as a result the interval of integer of capacitor switching is $\left[\underline{z}_{c, j}, \bar{z}_{c, j}\right]$. Suppose $\underline{z}_{c, j}=0$ generally.

From (2): $2^{2_{j,-1}}<\bar{z}_{c, j}-0 \leq 2^{k_{j}}$, As a result the length of the binary string needed in node $\mathrm{i}_{\mathrm{j}}$ is $\mathrm{k}_{\mathrm{j}}(\mathrm{j}=1,2, \cdots, \mathrm{n})$.

The coding of capacitors switching in $\mathrm{n}$ nodes is:

$$
c_{n, k_{n}-1} c_{n, k_{n}-2} \cdots c_{n, 0}\left|c_{n-1, k_{n-1}-1} c_{n-1, k_{1-1}-2} \cdots c_{n-1,0}\right| \cdots \cdots \cdot c_{1, k_{1}-1} c_{1, k_{1}-2} \cdots c_{1,0}
$$

c is binary number such as 0 and 1 . From (3) and (4), the number $z_{j}(j=n, n-1, \cdots 1)$ of capacitor switching in node $i_{j}$ can be solved from left to right, and combining with he equivalent susceptance of capacitors in node $i_{j}, c_{e, j}$, the susceptance value $c_{j}$ of capacitor switching can also be solved. This coding of capacitor switching also implicit the inequality constraint of capacitor switching, $\underline{\boldsymbol{c}}_{j} \leq \boldsymbol{c}_{j} \leq \overline{\boldsymbol{c}}_{j}$.

4.1.3. The Coding of Discrete Variable-transformer Tap Ratio: Similar to the coding of capacitor switching, The coding of transformer tap ratio is:

$\mathrm{b}$ is binary number such as 0 and 1 .

$$
b_{n, k_{n}-1} b_{n, k_{n}-2} \cdots b_{n, 0}\left|b_{n-1, k_{n-1}-1} b_{n-1, k_{n-1}-2} \cdots b_{n-1,0}\right| \cdots \cdots \cdot b_{1, k_{1}-1} b_{1, k_{1}-2} \cdots b_{1,0}
$$

4.1.4. The Integrated Coding of Transformer Tap Ratio and Capacitor switching: The model of discrete variable optimization (1.1) contains both two discrete variables-capacitor switching and transformer tap ratio, so the integrated coding of capacitor switching and transformer tap ratio is given:

Short for:

$$
\begin{gathered}
b_{n, k_{n}-1} b_{n, k_{n}-2} \cdots b_{n, 0}\left|b_{n-1, k_{n-1}-1} b_{n-1, k_{n-1}-2} \cdots b_{n-1,0}\right| \cdots \cdots \mid b_{1, k_{1}-1} b_{1, k_{1}-2} \cdots b_{1,0} \\
|| c_{n, k_{n}-1} c_{n, k_{n}-2} \cdots c_{n, 0}\left|c_{n-1, k_{n-1}-1} c_{n-1, k_{n-1}-2} \cdots c_{n, 0}\right| \cdots \cdots \mid c_{1, k_{1}-1} c_{1, k_{1}-2} \cdots c_{1,0}
\end{gathered}
$$

$$
B_{n} B_{n-1} \cdots \cdots \cdot B_{1} \| C_{n} C_{n-1} \cdots \cdots \cdot C_{1}
$$

\subsection{Fitness Function}

From section 3, the solve of the model of optimization can be divided into the solve of model of discrete variable optimization and model of continuous variable optimization respectively, and put into cross iteration until convergence. Whatever the model of optimization (1.1) and (1.2), they are both multi-objective optimization. Put negative sign to the three functions of minimization $F_{1} 、 F_{2} 、 F_{3}$, to change them to three functions of maximization, and define them as $\mathrm{Z}_{\mathrm{F} 1} 、 \mathrm{Z}_{\mathrm{F} 2}$ and $\mathrm{Z}_{\mathrm{F} 3}$ :

$$
\begin{aligned}
& Z_{F 1}\left(\boldsymbol{V}_{g}, \boldsymbol{c}, \boldsymbol{b}\right)=\max \left(-F_{1}\right) \\
& Z_{F 2}\left(\boldsymbol{V}_{g}, \boldsymbol{c}, \boldsymbol{b}\right)=\max \left(-F_{2}\right) \\
& Z_{F 3}\left(\boldsymbol{V}_{g}, \boldsymbol{c}, \boldsymbol{b}\right)=\max \left(-F_{3}\right)
\end{aligned}
$$

The key is how to solve the weight coefficient of every objective of the multi-objective optimization. This paper uses the method of genetic algorithm with adaptive weight to solve the problem of multi-objective optimization presented by reference[12], which takes advantage of genetic algorithm , and give out strategies with adaptive weight as numbers evolving and adaptive weight changing all time.

In the method of genetic algorithm, each generation produces a quite number of individuals to form a population $\mathrm{P}$. the maximum and the minimum of the optimization target of all individuals of current population $\mathrm{Z}_{\mathrm{F} 1}$ is:

$$
\begin{aligned}
& z_{F 1}^{\max }=\max \left\{-F_{1}\left(\boldsymbol{V}_{g, j}, \boldsymbol{c}_{j}, \boldsymbol{b}_{j}\right) \mid \boldsymbol{V}_{g, j}, \boldsymbol{c}_{j}, \boldsymbol{b}_{j} \in P\right\} \\
& z_{F 1}^{\min }=\min \left\{-F_{1}\left(\boldsymbol{V}_{g, j}, \boldsymbol{c}_{j}, \boldsymbol{b}_{j}\right) \mid \boldsymbol{V}_{g, j}, \boldsymbol{c}_{j}, \boldsymbol{b}_{j} \in P\right\}
\end{aligned}
$$


$\mathrm{V}_{\mathrm{g}, \mathrm{j}}, \mathrm{c}_{\mathrm{j},}, \mathrm{b}_{\mathrm{j}}$ are set voltage of controlled bus voltage, capacitor switching and transformer tap ratio of the coding of any individual $\mathrm{j}$ in population.

Similarly $z_{F 2}^{\max }, z_{F 2}^{\min }, z_{F 3}^{\max }$ and $z_{F 3}^{\min }$ are given.

In current population, every adaptive weight of each optimization can be represented as follows:

$$
w_{k}=\frac{1}{z_{F k}^{\max }-z_{F k}^{\min }}, k=1,2,3
$$

For $\mathrm{V}_{\mathrm{g}, \mathrm{j}}, \mathrm{c}_{\mathrm{j}}, \mathrm{b}_{\mathrm{j}}$ of certain individual $\mathrm{j}$ of a population, there are:

$$
\begin{aligned}
z_{F 1} & =F_{1}\left(\boldsymbol{V}_{g, j}, \boldsymbol{c}_{j}, \boldsymbol{b}_{j}\right) \\
z_{F 2} & =F_{2}\left(\boldsymbol{V}_{g, j}, \boldsymbol{c}_{j}, \boldsymbol{b}_{j}\right) \\
z_{F 3} & =F_{3}\left(\boldsymbol{V}_{g, j}, \boldsymbol{c}_{j}, \boldsymbol{b}_{j}\right)
\end{aligned}
$$

The objective function of genetic algorithm with adaptive weight is:

$$
z\left(\boldsymbol{V}_{g, j}, \boldsymbol{c}_{j}, \boldsymbol{b}_{j}\right)=\sum_{k=1}^{3} w_{k}\left(z_{F k}-z_{F k}^{\text {min }}\right)
$$

The inequality constraints are given by adaptability penalty function, such as:

$$
I_{l} \leq I_{l, \max }\left|V_{i}\right| \leq V_{\max } \text { or }\left|V_{i}\right| \leq-V_{\min }
$$

The constraint (6) can be given as $g_{i}\left(V_{g}, c, b\right) \leq b_{i}, i=1,2, \cdots, M$.

For individual $\mathrm{V}_{\mathrm{g}, \mathrm{j}}, \mathrm{c}_{\mathrm{j}}, \mathrm{b}_{\mathrm{j}}$, the adaptability penalty function is:

$$
p\left(\boldsymbol{V}_{g, j}, \boldsymbol{c}_{j}, \boldsymbol{b}_{j}\right)=1-\frac{1}{\mathrm{M}} \sum_{i=1}^{\mathrm{M}}\left(\frac{\Delta b_{i}\left(\boldsymbol{V}_{g, j}, \boldsymbol{c}_{j}, \boldsymbol{b}_{j}\right)}{\Delta b_{i}^{\max }}\right)
$$

where:

$$
\begin{gathered}
\Delta b_{i}\left(\boldsymbol{V}_{g, j}, \boldsymbol{c}_{j}, \boldsymbol{b}_{j}\right)=\max \left\{0, g_{i}\left(\boldsymbol{V}_{g, j}, \boldsymbol{c}_{j}, \boldsymbol{b}_{j}\right)-b_{i}\right\} \\
\Delta b_{i}^{\max }=\max \left\{\varepsilon, \Delta b_{i}\left(\boldsymbol{V}_{g, j}, \boldsymbol{c}_{j}, \boldsymbol{b}_{j}\right) \mid \boldsymbol{V}_{g, j}, \boldsymbol{c}_{j}, \boldsymbol{b}_{j} \in P\right\}
\end{gathered}
$$

$\Delta b_{i}\left(\boldsymbol{V}_{g, j}, \boldsymbol{c}_{j}, \boldsymbol{b}_{j}\right)$ is the violation value of individual $\mathrm{Vg}, \mathrm{j}, \mathrm{cj}$, bj to the i-th constraint. $\Delta b_{i}^{\max }$ is the maximum violation value of all individuals of current population to the constraint i. $\varepsilon$ is a small positive number, to avoid the situation that divided by zero in penalty function.

According to (5) and (7), for individual $\mathrm{V}_{\mathrm{g}, \mathrm{j}}, \mathrm{c}_{\mathrm{j}}, \mathrm{b}_{\mathrm{j}}$, the fitness function with penalty function inside is:

$$
F i t\left(\boldsymbol{V}_{g, j}, \boldsymbol{c}_{j}, \boldsymbol{b}_{j}\right)=z\left(\boldsymbol{V}_{g, j}, \boldsymbol{c}_{j}, \boldsymbol{b}_{j}\right) p\left(\boldsymbol{V}_{g, j}, \boldsymbol{c}_{j}, \boldsymbol{b}_{j}\right)
$$

\subsection{The Set of Other Operation Strategies and Related Parameters}

The related parameters of genetic algorithm need to be set, such as the scale of population, selectivity rate, cross rate, mutation rate and retention rate, which may have impact on the final results of optimization.

The set of cross rate and mutation rate are the most important. This paper uses the adaptive set of cross rate and mutation rate, which can make the optimization tend to global convergence at a very fast pace and a larger probability. At the beginning of the genetic evolution, the cross rate should be set higher, and the mutation rate should be set lower to ensure the calculation process move smoothly. At the ending of the genetic evolution, the chromosome of the population has been stable, and the calculation process may convergent to an local optimal solution. At this time the cross rate could be set lower and the mutation rate

should be set higher in order to get out of the local optimal solution. The formulas of the adaptive set of cross rate and mutation rate are:

$$
\begin{gathered}
P_{c}^{(k)}=P_{c}^{(0)}-\left(P_{c}^{(0)}-P_{c, \text { min }}\right) \exp \left(-\Delta u / N_{c}\right) \\
P_{m}^{(k)}=P_{m}^{(0)}-\left(P_{m}^{(0)}-P_{m, \text { max }}\right) \exp \left(-\Delta u / N_{m}\right)
\end{gathered}
$$

Where:k stands for algebra of genetic evolution, $\Delta \mathrm{u}$ is the difference between maximum and minimum values of the fitness function which contains the chromosome of 
the (k-1)-th generation. $P_{c}^{(0)}, P_{c}^{(k)}, P_{m}^{(0)}, P_{\mathrm{m}}^{(k)}$ stand for the initial value and the value of the $\mathrm{k}$-th generation of the cross rate and mutation rate. The initial value is: $P_{c}^{(0)}=0.9, P_{m}^{(0)}=0.001$. $P_{c, \text { min }}, P_{\mathrm{m}, \max }$ stand for the minimum value of the cross rate and the maximum value of the mutation rate, and are respectively set $0.6,0.1$. $\mathrm{Nc}$ and $\mathrm{Nm}$ are given constants, to simulate the speed level of change of cross rate and mutation rate with the dispersion of the fitness function. The dispersion lower, the cross rate lower and the mutation rate higher.

The set of the scale of population, selectivity rate and retention rate is given combining the specific examples as follows.

\section{Simulation Example}

The simulation is based on the reactive power optimization of large-scaled wind power base integration in Gansu Jiuquan of China[10].

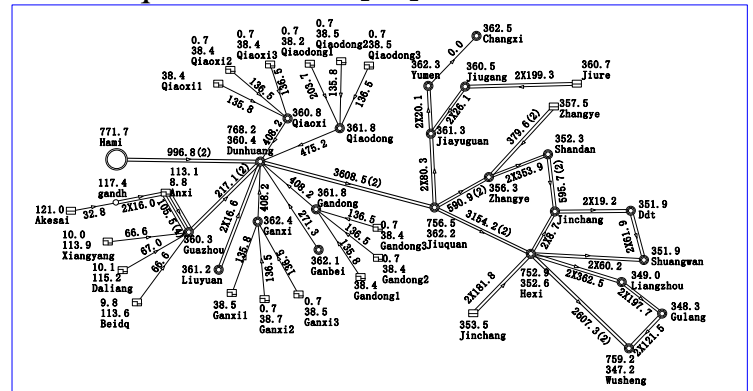

Figure 1. The Schematic Diagram of Access and Transmission of the Wind Power in Jiuquan

As Fig.1 says, most wind farms in Jiuquan wind power base are connected to the grid via two step-up transformers $0.69 \mathrm{kV} / 35 \mathrm{kV}, 35 \mathrm{kV} / 330 \mathrm{kV}$, and are sent out vie the long passage: Dunhuang-Jiuquan-Hexi-Wusheng $750 \mathrm{kV}$, such as $1 \mathrm{st}, 2 \mathrm{ed}, 3 \mathrm{rd}$ wind farm in Ganxi, 1st,2ed,3rd wind farm in Gandong, 1st,2ed,3rd wind farm in Qiaoxi, 1st,2ed,3rd wind farm in Qiaodong. Every wind farm has the installed capacity of about 200MW. The fluctuant wind power is sent out via the long transmission passage, which will have an impact on the reactive power balance of the passage and will bring the problem of increasing power loss, voltage fluctuation and voltage instability.

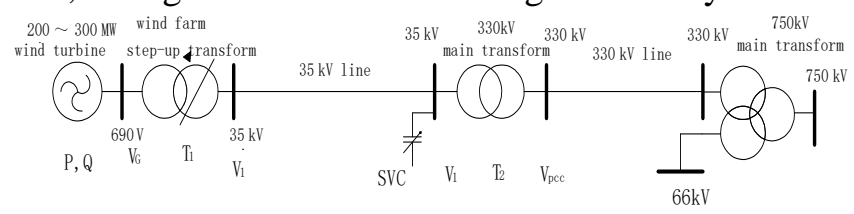

Figure 2. Typical Wiring and Location of Dynamic Reactive Power Compensation Diagram in Jiuquan Wind Farm

As Fig.2 says, DRPC devices are set at the side of $35 \mathrm{kV}$ of the step-up transformer of every wind farm, which are in control of the $330 \mathrm{KV}$ bus voltage of the high-voltage side of the step-up transformer. That means the control bus of the DRPC devices is the bus of $330 \mathrm{kV}[11]$. The numbers of DRPC devices are twelve. The capacitive capacity of the DRPC devices of every wind farm in Jiuquan wind power base is $20 \%$ of the installed capacity of wind farm, and the inductance capacity is $30 \%$ of the capacitive capacity.

Not just the DRPC devices are continuous control equipments, there are also other continuous control equipments such as: the terminal bus voltage of six generator units in Jiure, Zhangye and Jinchang power plant, and the upper and lower of the reactive power of the generator is $1 / 3$ of the rated active power. The main discrete control equipments are 
mechanical low-voltage compensation devices and adjustable transformer tap in the $750 \mathrm{kV}$ Dunhuang, Jiuquan, Hexi and Wusheng substation in Fig.1.

The algorithmic routine about this study is written by $\mathrm{C}++$.

Tab.1 gives out the power loss, voltage quality and load margin before optimization.

Table 1. Value of Objectives before Optimization

\begin{tabular}{|l|l|}
\hline objectives & calculated value(p.u.) \\
\hline power loss(p-loss) & 0.0634 \\
\hline voltage quality(v-quality) & 0.01983 \\
\hline load margin(1-margin) & 7.28874 \\
\hline
\end{tabular}

Solve the continuous variable optimization and discrete variable optimization respectively, and put into cross iteration until convergence and get the optimal control solution. Tab. 2 gives out the coding of continuous variables and discrete variables:

Table 2. Coding of Control Variables

\begin{tabular}{|l|l|l|l|l|l|}
\hline & $\begin{array}{l}\text { adjusta- } \\
\text { ble step }\end{array}$ & $\begin{array}{l}\text { lower } \\
\text { (p.u.) }\end{array}$ & $\begin{array}{l}\text { upper } \\
\text { (p.u.) }\end{array}$ & $\begin{array}{l}\text { coding } \\
\text { length } \\
\text { of unit }\end{array}$ & $\begin{array}{l}\text { total length } \\
\text { (unit length } \times \\
\text { device number }\end{array}$ \\
\hline generator & 0.01 & 0.90 & 1.10 & 5 & $5 \times 6=30$ \\
\hline DRPC & 0.01 & 0.90 & 1.10 & 5 & $5 \times 12=60$ \\
\hline transformer & 0.02 & 0.90 & 1.10 & 4 & $4 \times 4=16$ \\
\hline capacitor & 0.01 & 0.00 & 0.20 & 5 & $5 \times 4=20$ \\
\hline $\begin{array}{l}\text { coding length of } \\
\text { continuous } \\
\text { variable }\end{array}$ & 90 & $\begin{array}{l}\mid l \\
\text { coding length of } \\
\text { discrete variable }\end{array}$ & 36 &
\end{tabular}

After operation for many times, the better set parameter of searching performance of genetic algorithm is get. The population scale is 60 , the selectivity rate is 0.6 , the retention rate is $0.05 \sim 0.1$, the cross rate and mutation rate are given adaptively as mentioned earlier. Tab.3 gives out the information of time consuming and iteration number of genetic solution algorithm.

\section{Table 3. Statistic for Time Consuming and Iteration Number of Genetic Solution Algorithm}

\begin{tabular}{|l|l|}
\hline $\begin{array}{l}\text { time consuming of continuous } \\
\text { variable optimization (1time) }\end{array}$ & $12(\mathrm{~m})$ \\
\hline $\begin{array}{l}\text { time consuming of discrete variable } \\
\text { optimization (1 time) }\end{array}$ & $10(\mathrm{~m})$ \\
\hline iteration number & 5 times \\
\hline total time consuming & $22 \times 5=110(\mathrm{~m})$ \\
\hline
\end{tabular}

After 5 times' iteration optimization of discrete variable and continuous variable, and get the optimal solution after convergence. Tab.4 gives out the optimal solution of control variables:

Table 4-1. Optimal Solution of Control variables

\begin{tabular}{|l|l|l|l|l|l|}
\hline generator & $\begin{array}{l}\text { termina } \\
-1 \text { bus } \\
\text { voltage }\end{array}$ & substation & $\begin{array}{l}\text { transfor- } \\
\text { mer } \\
\text { tap ratio }\end{array}$ & substation & $\begin{array}{l}\text { capacitor } \\
\text { susceptan- } \\
\text { ce }\end{array}$ \\
\hline Jiure\#1 & 1.04 & Dunhuang & 1.00 & Dunhuang & 0.20 \\
\hline Jiure\#2 & 1.04 & Jiuquan & 1.02 & Jiuquan & 0.12 \\
\hline Zhangye\#1 & 1.02 & Hexi & 0.96 & Hexi & 0.08 \\
\hline Zhangye\#2 & 1.02 & Wusheng & 0.94 & Wusheng & 0.06 \\
\hline Jinchang\#1 & 1.08 & & & & \\
\hline
\end{tabular}




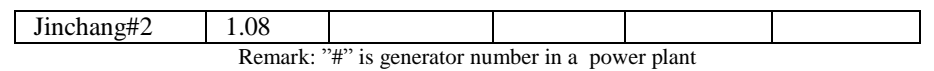

Table 4-2. Optimal Solution of Control Variables

\begin{tabular}{|c|c|c|c|}
\hline DRPC & $\begin{array}{l}\text { controlled bus } \\
\text { voltage }\end{array}$ & DRPC & $\begin{array}{l}\text { controlled bus } \\
\text { voltage }\end{array}$ \\
\hline Ganxi\#1 & \multirow{3}{*}{1.06} & Gandong\#1 & \multirow{3}{*}{1.08} \\
\hline Ganxi\#2 & & Gandong\#2 & \\
\hline Ganxi\#3 & & Gandong\#3 & \\
\hline DRPC & $\begin{array}{l}\text { controlled bus } \\
\text { voltage }\end{array}$ & DRPC & $\begin{array}{l}\text { controlled bus } \\
\text { voltage }\end{array}$ \\
\hline Qiaoxi\#1 & \multirow{3}{*}{1.05} & Qiaodong\#1 & \multirow{3}{*}{1.04} \\
\hline Qiaoxi\#2 & & Qiaodong\#2 & \\
\hline Qiaoxi\#3 & & Qiaodong\#3 & \\
\hline
\end{tabular}

Every optimal objectives after optimization has greatly improved comparing with every optimal objectives before optimization, as Tab.5:

\section{Table 5. Value of Objective after Optimization}

\begin{tabular}{|l|l|}
\hline objectives & calculated value (p.u.) \\
\hline power loss(p-loss) & 0.0609 \\
\hline voltage quality(v-quality) & 0.00645 \\
\hline load margin(l-margin) & 7.45082 \\
\hline
\end{tabular}

(a), (b) and (c) in Fig.3 gives out the process of the objectives approaching the optimal objectives with the grow of iteration number.

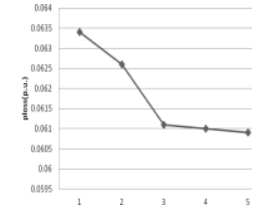

(a) iteration of p-loss

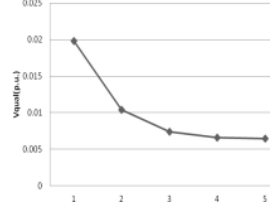

(b) iteration of v-quality

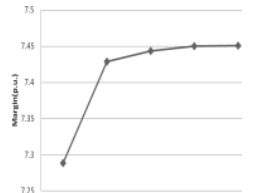

(c) iteration of 1-margin

Figure 3. Iteration Process of Solving for Reactive Power Optimization

\section{Conclusion}

This paper aims at the problems which were brought by large-scale wind power integration, considering the coexistence of DRPC devices, the terminal bus voltage of conventional generators and other continuous equipment, and the coexistence of mechanical low-voltage compensation devices, adjustable transformer tap ratio and other discrete equipment, and creates the model of multi-objective reactive power optimization of power loss, voltage quality and voltage stability, gives out a thinking of solving model of multi-objective reactive power optimization based on genetic algorithm with adaptive weight. The study gives out the strategy of coordinative optimization of discrete variables and continuous variables, and the operation strategy of the coding of genetic algorithm, cross and variation, and adaptive determined method of multi-objective weight in the process of genetic algorithm, writes an algorithm program using $\mathrm{C}++$, gives the simulation of multi-objective reactive power optimization based on the large-scale wind power base integration in Gansu Jiuquan of China and confirms the certainty of this model. 


\section{References}

[1] Y. H. Ma, N. B. Wang, S. E. He, G. T. Liu and F. C. Liu, "The Current Situation and Prospect for Jiuquan 10GW Wind Power Base", Power System and Clean Energy, vol. 25, no. 11, (2009), pp. 76-79.

[2] Y. N. Chi, Y. H. Liu, W. S. Wang, M. Z. Chen and H. Z. Dai, "Study on Impact of Wind Power Integration on Power System", Power System Technology, vol. 31, no. 3, (2007).

[3] W. Shi, H. Wei and X. Q. Bai, "Reactive Power Optimization in Large-scale Power Systems with Discrete Variables", Electric Power Automation Equipment, vol. 27, no. 3, (2007), pp. 41-45.

[4] Y. Cheng and M. B. Liu, "Reactive-power Optimization of Large-scale Power Systems with Discrete Control Variables", Proceedings of the CSEE, (2002).

[5] Y. T. Hsiao, C. C. Liu and H. D. Chiang, "A New Approach for Optimal VAR Sources Planning in Large Scale eElectric Power Systems”, IEEE Trans on Power Systems, vol. 8, no. 3, (1993), pp. 988996.

[6] X. S. Zhang, Z. Liu and E. K. Yu, "The Strategy of Distribution Capacitor Scheme based on Tabu Search”, Power System Technology, vol. 22, no. 2, (1998), pp. 33-36.

[7] S. X. Zhou and B. Yang, "A New Algorithm for Reactive Power Optimization-Genetic Algorithms", Automation of Electric Power Systems, vol. 19, no. 11, (1995), pp. 19-23.

[8] Q. Wang and G. F. Fang, "Multi-objective Reactive Power Optimization Considering Voltage Stability", Automation of Electric Power Systems, vol. 23, no. 3, (2001), pp. 31-34.

[9] X. L. Liu, J. W. Li, X. G. Cheng and L. X. Cao, "A New Method to Determine Optimal Secure Operating Point of Power Systems”, Power System Technology, vol. 29, no. 8, (2005), pp. 56-60.

[10] N. B. Wang, J. D. Wang and S. E. He, "Cross-border Accommodation Method and Transmission Scheme of Jiuquan Wind Power", Automation of Electric Power Systems, vol. 35, no. 22, (2011), pp. 82-89

[11] Y. Yang, R. Qin and R. Q. Bai, "Optimizing Application of Dynamic Reactive Power Compensation Devices in Jiuquan Wind Farms", Power System and Clean Energy, vol. 28, no. 4, (2012), pp. 81-85.

[12] M. S. Gen, R. W. Cheng, "Genetic Algorithms and Engineering Optimization", Beijing: Tsinghua University Press, (2004), pp. 76-108.

[13] J. R. O. Soto, C. R. R. Domellas and D. M. Falcao, "Optimal Reactive Power Dispatch Using a Hybrid Formulation: Genetic Algorithms and Interior Point", IEEE Porto Power Tech Proceedings, (2001); Porto, Portugal.

\section{Author}

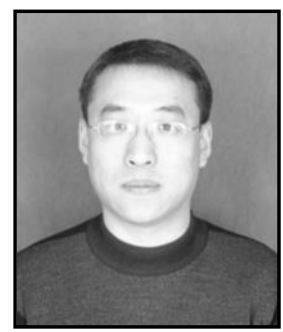

Deyu Chen, he was born in 1974 . He received the automation $\mathrm{Ph} . \mathrm{D}$. degrees from Harbin Engineering University in 2010. His research interests are in automation control, multi-agent modelling. 
International Journal of Control and Automation Vol. 8, No.4 (2015) 